\title{
A Review of Grid-Tied Converter Topologies Used in Photovoltaic Systems
}

\author{
W. Xiao ${ }^{1}$, M. S. El Moursi ${ }^{1 *}$, O. Khan ${ }^{1}$, and D. Infield ${ }^{2}$ \\ ${ }^{1}$ Department of Electrical Engineering and Computer Science, Masdar Institute of Science and \\ Technology, Abu Dhabi, UAE \\ ${ }^{2}$ Department of Electronic \& Electrical Engineering, University of Strathclyde, 16 Richmond Street, \\ Glasgow, Scotland, United Kingdom \\ *melmoursi@masdar.ac.ae
}

\begin{abstract}
This study provides review of grid-tied architectures used in photovoltaic power systems, classified by the granularity level at which maximum power point tracking (MPPT) is applied. Grid-tied PV power systems can be divided into two main groups, namely centralized MPPT (CMPPT) and distributed MPPT (DMPPT). The DMPPT systems are further classified according to the levels at which MPPT can be applied, i.e. string, module, submodule, and cell level. Typical topologies for each category are also introduced, explained and analyzed. The classification is intended to help readers understand the latest developments of grid-tied PV power systems and inform research directions.
\end{abstract}

\section{Introduction}

With the increasing capacity of photovoltaic (PV) power systems integrated into grids, the classification of PV systems becomes a useful tool for understanding PV system design and also to inform research aimed at improving system performance.

Grid-connected PV systems are traditionally classified by power capacity, which are listed as small-scale, intermediate-scale, and large-scale, [1]. PV generators that are less than $50 \mathrm{~kW}$ are usually considered as small scale PV systems. A system that can produce more than $1 \mathrm{MW}$ is commonly considered as large-scale or utility-scale, although this category now covers systems up to tens or even hundreds of MW. Systems between these two ranges are designated as intermediate-scale.

Recent classification focuses also on voltage levels at the point of common coupling (PCC). Low-voltage (LV) connected systems are usually either small-scale or medium scale, and installed close to the electricity users, such as within the home or office buildings, [2]. Motivated by local tariff structures, these systems are usually sized to meet the local electrical requirement without significant export to the grid. Except for the active power injection, other functions of grid support are generally not required from such systems, [3]. The power output is mainly controlled by the function of maximum power point tracking (MPPT). The grid-tied converter is normally required to maintain unity power factor and is controlled to prevent islanding in the case of loss of grid, [4-6].

Generating plant supplying power to medium-voltage (MV) networks can be required to contribute to network support and maintain the security and reliability of network operation, [7, 8]. Such utility-scale systems should contribute to voltage stability in the MV network, [9]. The inverters are 
This article has been accepted for publication in a future issue of this journal, but has not been fully edited.

generally required to operate within a power factor range of 0.95 leading or lagging, [10-13]. The functions of active power regulation and fault ride through (FRT) are also recommended by European grid codes, [14-18].

Converter topologies used can overlap the above classification. For example, the topology of the classic voltage source inverter (VSI) can be used for the small-scale, medium-scale or large-scale grid integration. The same topology can be utilized for the LV grid connection or MV grid connection through step-up transformers. It is important to have a criterion to clearly distinguish the system architectures and topologies. In this review, all grid-tied systems are classified by the function of MPPT in terms of centralized MPPT (CMPPT) and distributed MPPT (DMPPT). It provides a clear framework for understanding the grid-tied architectures and topologies used for photovoltaic systems.

\section{Centralized Maximum Power Point Tracking Systems}

A PV array comprises modules that are connected in series-parallel combination to meet the input voltage requirement of the centralized power inverter for grid connection, and achieve the desired rated power. The maximum power point tracking in such systems is operated by a centralized inverter at array level. Such structures are referred to as centralized maximum power point tracking (CMMPT) systems, [19-21]. Galvanic isolation is required by some grid codes due to the requirement for a grounded system. A PV grounded system is defined as one where the DC conductors (either positive or negative) are connected to a grounding system, which in turn is connected to the earth.

Typical architectures of such systems are shown in Fig. 1. The DC/AC stage can be connected to single phase or three phase networks depending on the configuration at the PCC. A three-stage conversion system is illustrated in Fig. 1 (a), of which the conversion sequence is formed as DC to high frequency HFAC to DC to LFAC. The terms of HFAC and LFAC refer to high frequency AC and low frequency $\mathrm{AC}$ respectively. The topology generally adopts high frequency transformers, which have advantages of small size, low weight, and low cost.

Fig. 1 (b) shows a two-stage conversion system that uses a low frequency transformer at the output stage. The multi-stage interfacing topologies include intermediate DC links (IDCL), which interface the $\mathrm{DC} / \mathrm{DC}$ and DC/AC units. The IDCL is formed by a capacitor bank to mitigate significant LFAC ripples. High capacitance in IDCL can decouple the dynamic interaction between the DC/DC and DC/AC stages [22]. Low frequency transformers, or so called line frequency transformers, are bulky and heavy, but are robust and provide galvanic isolation exactly at the point of common coupling (PCC). Fig. 1 (c) shows a one-stage conversion system that converts the PV array output directly to AC through the PV inverter and low frequency transformer. The recent grid codes allow ungrounded PV systems, which make use of non-isolated or transformer-less inverters, [23]. Without any transformer loss, the 

system aims for higher efficiency than the isolated counterparts. Two-stage and one stage conversion systems are shown in Figs.2 (a) and (b), respectively.

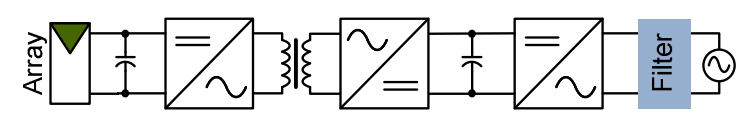

(a)

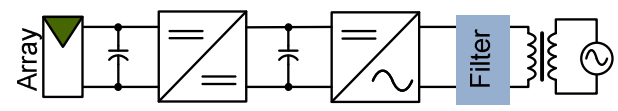

(b)

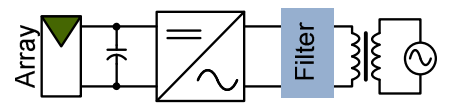

(c)

Fig. 1. Centralized maximum power point trackers with galvanic isolation

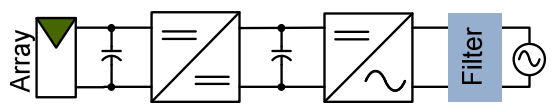

(a)

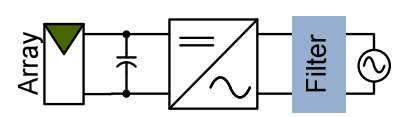

(b)

Fig. 2. Centralized maximum power point trackers without galvanic isolation.

In multiple-stage converters, the control of the front end power interface is mainly for maximum power point tracking. The DC/AC inverter at the grid-tied stage performs the dc-link voltage regulation and the grid-tied functions, which are defined by grid codes, [24, 25]. In the single-stage operation, the DC link is located at the PV array output terminal. A single-stage DC/AC inverter must be able to undertake both MPPT and other required grid-tied functions, $[14,26]$. The single-stage power interface has the advantage of simplicity and aims for higher conversion efficiency than a two-stage solution, [2730]. However, the DC link configuration in multiple stage conversion distributes the control into two individual tasks and provides flexibility to implement modular DC/DC MPPT units to achieve more effective energy harvesting, [31].

\section{Distributed Maximum Power Point Tracking Systems at PV String Level}

Significant power loss has been reported for CMPPT systems due to unbalanced generation among PV panels, [32-36]. The mismatch commonly results from clouds, or shadows of trees and buildings, dust covering, but also temperature differences, aging, or manufacturing imperfections. Mismatch has a disproportionate impact on system performance as the cell of module with the lowest output will limit the current through other elements in the string, [37, 38]. Thus, distributed MPPT (DMPPT) has attracted significant research attention to address the above issues. The distributed structure of maximum power point trackers have widely been accepted in commercial PV inverter products at the string level. 
This article has been accepted for publication in a future issue of this journal, but has not been fully edited.

The DMPPT solution is also adopted in DC microgrid configurations, [39]. A PV array typically comprises multiple strings connected in parallel. The concept of the string inverter has been introduced to avoid such mismatch between strings, [19, 40]. In contrast to CMPPT, the DC/AC grid-tied unit is rated and connected to individual PV strings instead of the whole PV array, [41, 42]. Solar energy is collected by the string inverters and supplied to the AC interconnection.

Fig. 3 illustrates another example of a grid-tied system with three distributed maximum power point trackers at the string level. The output of each string is modulated by an independent DC/DC converter, which acts as the maximum power point tracker. The DC bus can be linked to either a DC microgrid or an AC grid through a centralized DC/AC inverter. Therefore, the power degradation caused by any mismatch effect at string level is minimized. The DC/DC and DC/AC converters can be either independent units or integrated inside one enclosure. Some commercial systems implement the DC/DC units inside combiner boxes to perform independent string-level MPPT, [20, 43].

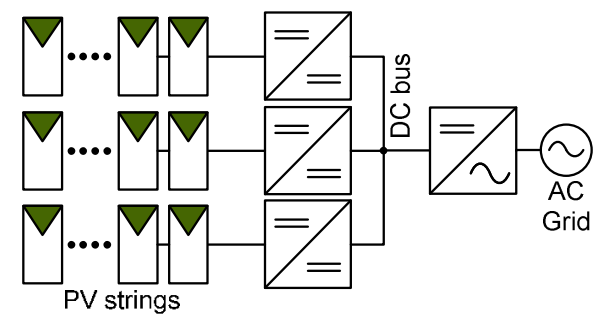

Fig. 3. Distributed maximum power point trackers at PV string level.

\section{A. PV Side Converter Topology}

The PV side converter refers to the DC/DC power stage that the input terminal is connected with PV generator. The converters are operated by the algorithm of maximum power point tracking (MPPT) for the highest solar energy harvesting. The schematics of the conventional non-isolated topologies are shown in Fig. 4 including buck, boost, and buck-boost DC/DC converters. The selection is based on the voltage levels of the PV side and the DC link. For example, the boost topology should be used if the PV terminal voltage is always lower than the DC link voltage with consideration of environmental impact on the PV output voltage. Boost converter topology is usually selected for the string-level power interface thanks to the claimed advantages for PV applications, [37, 44]. Similarly, the buck topology should be utilized for the condition that the input voltage is always higher than the output. Buck-boost topology should be only considered if the input and output voltage cannot be clearly distinguished as either step-up or step-down with the consideration of the environmental impact and the variation of the DC link voltage, [45-48]..

The isolated topologies are commonly based on the full bridges as shown in Fig. 5. The converter is conventionally utilized for high power level, which satisfy the requirement of the string level solution. 
The topology also matches the DC/DC power interface, which is shown as the application for CMPPT systems in Fig. 1 (a). The $\mathrm{H}$ bridge produces HFAC signal that can pass through the transformer. The winding turn ratio of the transformer provides the options for either stepping up or down the input voltage into the output terminal. The HFAC signal is rectified into DC form and connected to the DC link.

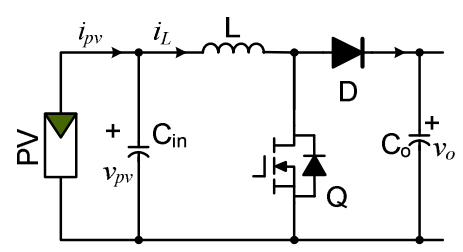

(a)

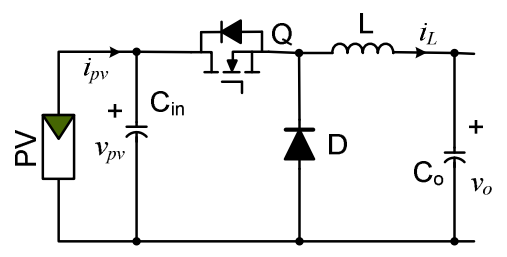

(b)

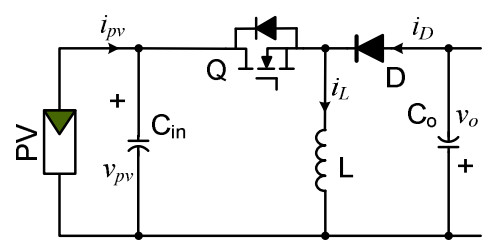

(c)

Fig. 4. Typical schematic circuits of non-isolated DC/DC converters

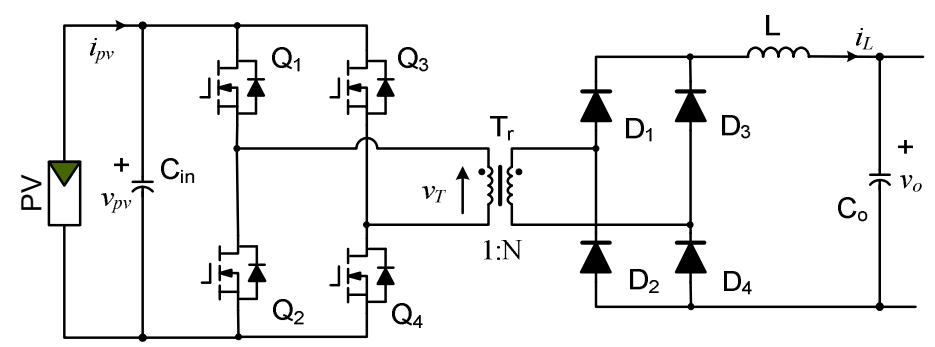

( a)

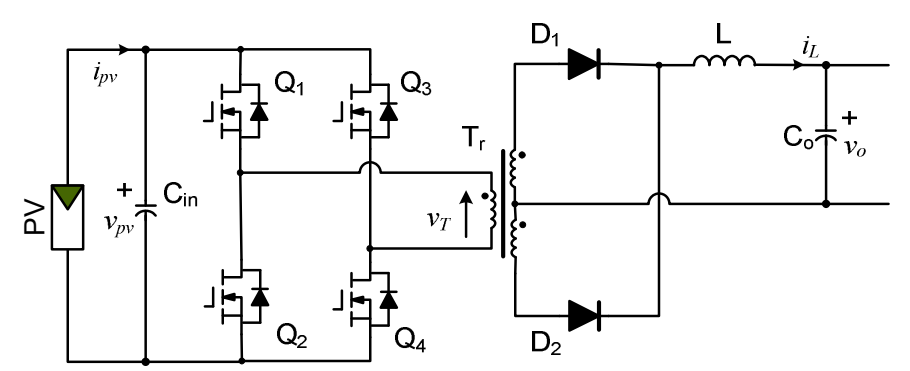

(b)

Fig. 5. Typical schematic circuits of isolated DC/DC converters 


\section{B. Grid Side Converter Topology}

Fig.6 illustrates the common DC/AC topologies used for grid connection, which include the H-bridge circuit for single-phase integration and the current source inverter (CSI) for three-phase integration [49].. In term of circuit schematics, the current source inverter (VSI) is the same as the voltage source inverter (VSI), which is commonly used for motor drives and three phase power supplies. The operation of pulse width modulation and control strategy makes different from the concept of CSI from VSI. For MV grid integration, step-up transformers can be utilized to boost from LV to MV. The DC link can either be the link between the PV side converter and the grid side converter or the PV terminal, which is defined as one stage conversion. The analysis of full bridge isolated converter can generally follow the same as the non-isolated buck converter, but it provides the function of galvanic isolation and flexibility to be designed for various conversion ratios thanks with the transformer implementation.

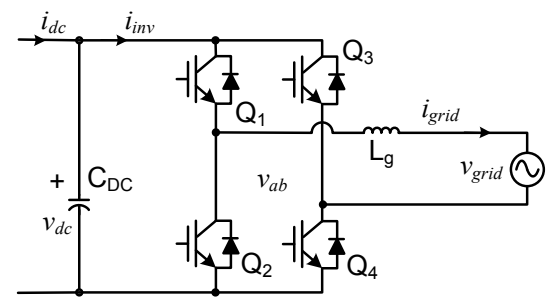

( a )

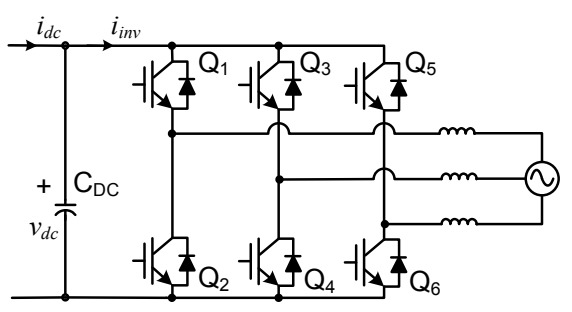

( b )

Fig. 6. Typical schematic circuits of DC/AC grid side converters

\section{AC filter}

AC filter is required to mitigate the harmonic injection from the grid side converters (GSC). Shown in Fig. 6, the inductive (L-type) filter is applied between the GSC and grids. The L-type filter is simple and robust from implementation and analysis. Recent study focuses more on the LCL filters, which are shown in Fig. 7. The filter shows the $3^{\text {rd }}$ order dynamics that can attenuate the switching frequency more effectively [50]. The total inductance is lower than the L-type in order to achieve the same filtering performance. Due to the self-resonant nature, a damping resistor is required in series with the capacitor to suppress oscillation, as shown in Fig. 7 (b). However, research focuses more on the active damping that is based on the circuit in Fig. 7 (a). The active damping can be achieved by 

advanced control algorithm to mitigate the self oscillation [50]. Another common filter type is the LC filter that is mainly used in VSI based systems. It is not discussed in details since it is not commonly used for grid interconnection, but is used in stand-alone PV power systems.

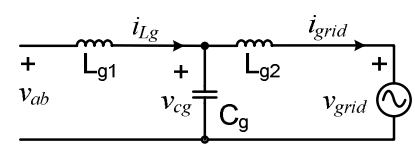

(a)

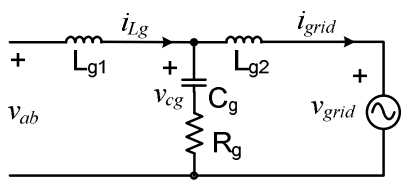

( b )

Fig. 7. Circuits of LCL filters for grid interconnecdtion

\section{Distributed Maximum Power Point Tracking Systems at PV Module Level}

Module integrated converters provide independent MPPT operation within each PV module, which allows local optimization and reduces power loss resulted from mismatch and partial shading, [37, 38, 51].

\subsection{Module-Integrated-Parallel Inverters}

Shown in Fig. 5 (a), the module-Integrated-Parallel Inverter (MIPI) integrates PV modules in parallel onto a common AC bus that is directly connected to the AC network, [52]. Such systems usually refer to PV micro-inverters or AC modules, which directly convert the PV module voltage of 22-45 V to the LV AC grid level, [19, 53-55]. The concept of AC modules refers to PV modules having AC output terminals since DC/AC stages are integrated inside the junction boxes of PV panels. However, the PV micro-inverter or MIPI can be an independent unit outside of the PV modules. The parallel interconnection completely eliminates the single point failure that is common in series connection. Meanwhile, the system becomes highly modular and flexible since the parallel structure can be easily expanded, [56, 57]. Besides the common merits of the parallel structure, the direct DC/AC conversion of MIPI shows the additional advantages of the lowest capacity for a DC/AC grid connection and simple system wiring since DC wiring is integrated at the module section and $\mathrm{AC}$ wiring is common for ordinary electricians. The drawback of MIPI is also clear since the overall system cost is higher than the centralized counterpart, the conversion efficiency is constrained due to the high DC/AC conversion ratio, the MPPT effectiveness is influenced by the impact of double-line frequency ripple in single-phase systems, and harsh outdoor operating environment influences the lifetime and reliability of the electronics, [58]. 


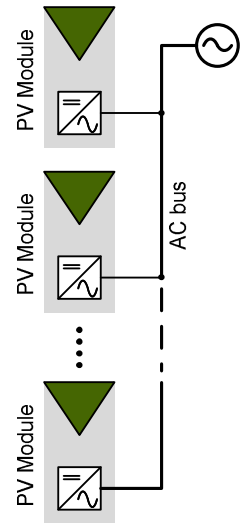

(a)

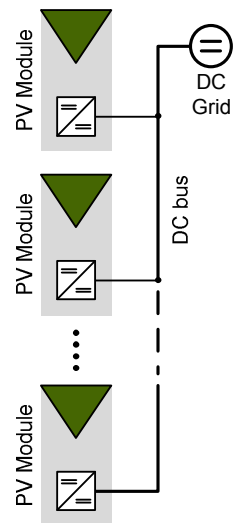

(b)

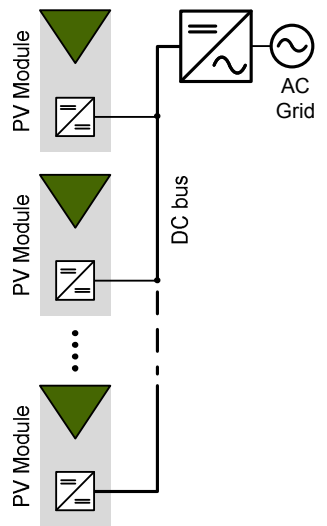

(c)

Fig. 8. Parallel configurations of distributed maximum power point trackers at PV module level.

Two-stage conversion is generally required due to the high conversion ratio of voltage required, [31, 59]. Shown in Fig. 6 (a), the DC-DC stage steps up the voltage from the PV module level to a near constant level for grid interconnection, [60]. The DC/AC unit converts the DC voltage to the AC line voltage through sinusoidal pulse width modulation (SPWM). Due to high capacitance across the DC link, the voltage is maintained to provide the buffer for energy transfer from DC to AC. One stage conversion has also been proposed to minimize conversion losses, [61]. Since the majority of MIPI are connected to a single phase AC grid, significant capacitance must be connected to the PV module terminal in order to mitigate double line frequency ripples. The drawbacks of high capacitance lie in the capacitor lifetime and slow system dynamics.

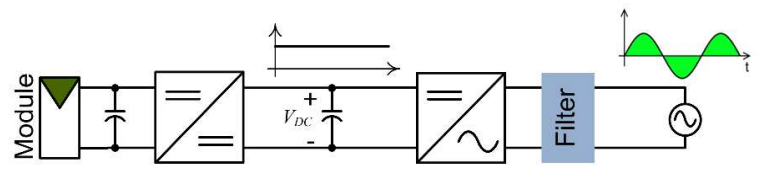

(a)

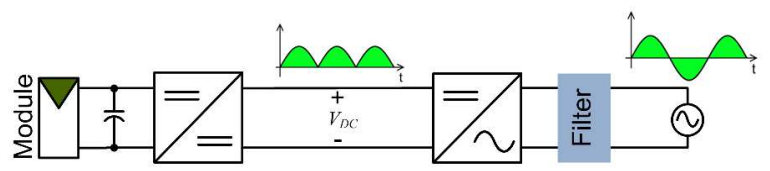

(b)

Fig. 9. Two types of module integrated parallel inverters: (a) with constant voltage DC link; (b) with pseudo DC link.

The Flyback DC/DC topology is commonly utilized as the front end interface of the MIPI and show the advantages of high conversion ratio, galvanic isolation, and low component count, [57, 58, 62]. The topology and its variation have been used for the DC-DC stage to inject PV energy into the constant voltage DC link, as shown in Fig. 6 (a). High switching frequency is used in both the DC/DC and DC/AC stages to perform PWM. Another solution, shown in Fig. 6 (b), does not maintain a steady DC link voltage, but allows the DC voltage to vary according to the rectified waveform of the sinusoidal line voltage, [63]. Therefore, the DC current produced by the flyback converter includes the significant 
Content may change prior to final publication in an issue of the journal. To cite the paper please use the doi provided on the Digital Library page.

variation of the double line frequency. The circuit schematic is shown in Fig. 7, where the DC current is converted to AC through a current unfolding circuit. Since the DC link voltage is no longer regulated to a constant level, the term pseudo DC link is referred to in the literature, $[56,63]$. The advantage lies in the low frequency switching of the unfolding circuit since PWM is no longer needed. However, due to the effect of double line frequency ripples in the single-phase interconnection, the capacitance rating at the PV module terminal is significant, e.g. $8.8 \mathrm{mF}$ in $[56,64]$. The topology, shown in Fig. 6 (a), is capable of minimizing the overall capacitance since the constant DC link voltage is significantly higher than the PV module voltage. Another solution, the so called multilevel energy buffer, is proposed to ease this problem, [64].

The topologies can be modified by interleaving the flyback converter to increase power capacity, [56]. For flyback topologies, high voltage stress can be expected on the output rectifier, which is introduced by the leakage inductance of the flyback transformer.

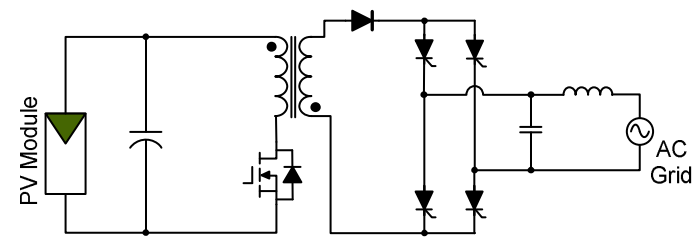

Fig. 10. Typical circuit of Module-Integrated-Parallel Inverter based on flyback topology

One special topology has been developed to construct the MIPI, as shown in Fig. 11, including four function blocks: the inverter, transformation stage, energy buffer, and cycloconverter, [65]. The circuit is more complicated than the flyback topology, but shows independent control over the capacitor voltage, soft switching of all power switching devices, and full four-quadrant operation. The conversion from $32 \mathrm{~V}$ DC to $240 \mathrm{~V} \mathrm{AC}$ is tested as $98 \%$ at the peak efficiency and $95.5 \%$ according to the CEC stamdard, which is a weighted efficiency that was defined by the California Energy Commission.

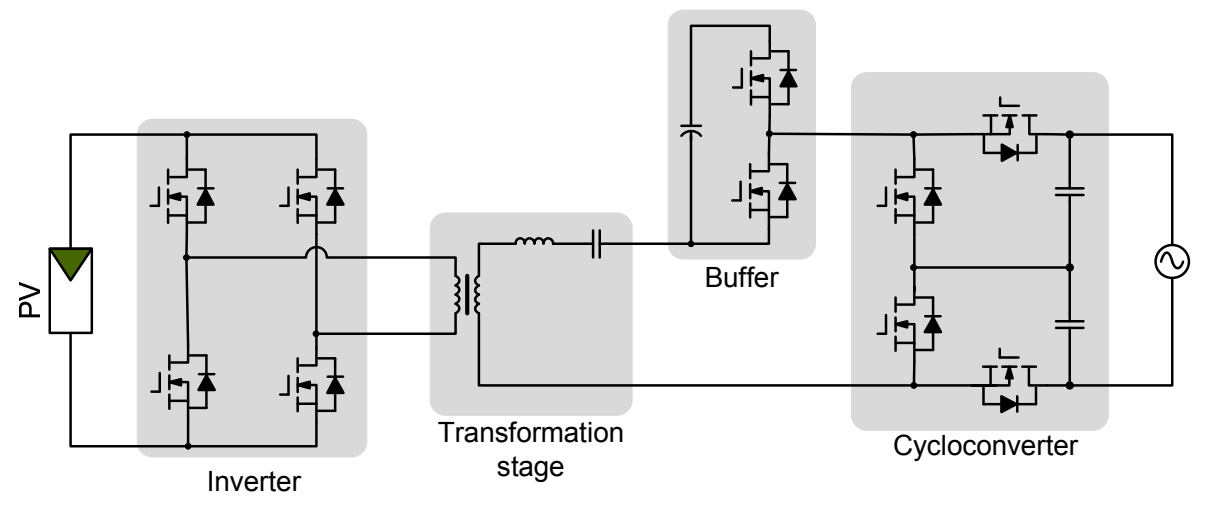

Fig. 11. Special circuit of Module-Integrated-Parallel Inverter 


\subsection{Module-Integrated-Parallel Converters}

Module-Integrated-Parallel Converters (MIPC) perform DC/DC conversion, which integrate PV modules in parallel onto a common DC bus. The DC bus can be linked to either DC microgrids or AC grids through a centralized DC/AC inverter, as shown in Fig. 5 (b) and Fig. 5 (c). The MIPC based PV systems take the advantage of the parallel structure of its counterpart, the MIPI. It provides the simplest solution for connection to a DC microgrid. It also has superior performance since the double-line frequency ripple is no longer present in the DC/DC conversion stage. However, for AC grid integration, the system becomes more complicated than the MIPI structure, but shares the same disadvantages as the MIPI system in terms of the high voltage conversion ratio, relatively low conversion efficiency, and harsh outdoor operating conditions.

A MIPC based system was commercially introduced by eIQ energy Inc., [66]. The tapped inductor topology was designed for high conversion gain and is shown in Fig. 12, [67-69]. The tapped inductor can be described as an autotransformer, which provides no galvanic isolation. Derived from the standard buckboost topology, the winding ratio of the tapped inductor offers flexibility to step up the DC/DC conversion to a relatively high level. It also utilizes an interleaved structure including two conversion phases, which reduces the filter size in both input and output ports. High voltage stress is always presented to the output rectifier, which can be made worse by the leakage inductance of the tapped inductor. Efficiencies as high as $98.3 \%$ and $99.1 \%$, have been reported in [67] and [70], respectively.

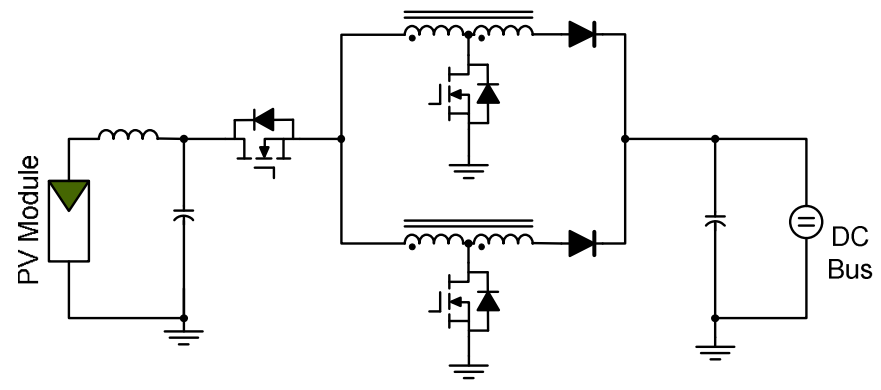

Fig. 12. Circuit of Module-Integrated-Parallel Converter proposed by eIQ energy Inc.

\subsection{Module-Integrated-Series Converters}

Module-integrated-series converters (MISC), also called DC power optimizers, are integrated with PV modules to perform MPPT and DC/DC conversion. The idea was originally proposed in [32, 33, 71]. However, the reported efficiency was not high enough to be adopted for practical implementation. More recently, thanks to the efficiency enhancement, commercial examples of MISC are now available from several companies, e.g. National Semiconductors, SolarEdge, Tigo, and Xandex ,[66]. 
In contrast to the MIPC, the outputs of MISCs are serially connected to form a common DC bus, as shown in Fig. 13 (a). The DC bus can be directly linked to either a DC microgrid or an AC grid through a centralized DC/AC inverter. The structure provides an ideal solution to support a DC microgrid. The stack structure can build up voltage and allow each MISC to be operated at a low conversion ratio that allows high conversion efficiency, [32]. The drawbacks are that the structure is not as flexible as the parallel configurations such as the MIPI and MIPC. The reliability can be a concern since the series connection cannot be immune to single point failure. The installation is mostly located in the outdoor environment similar to other DMPPT units at module level.

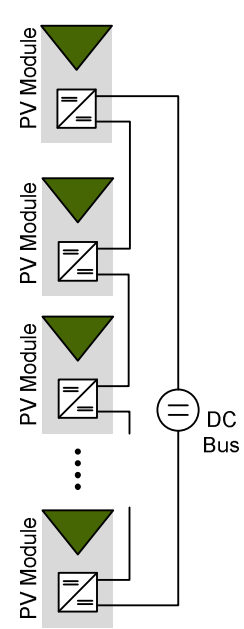

(a)

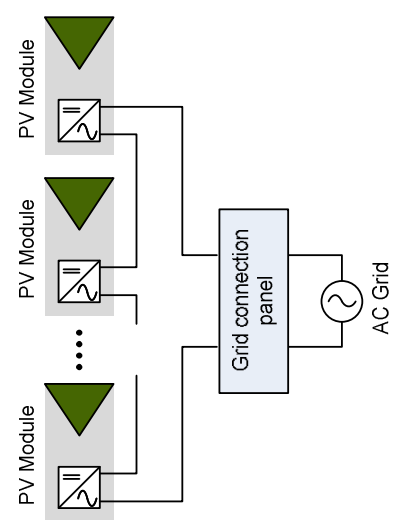

(b)

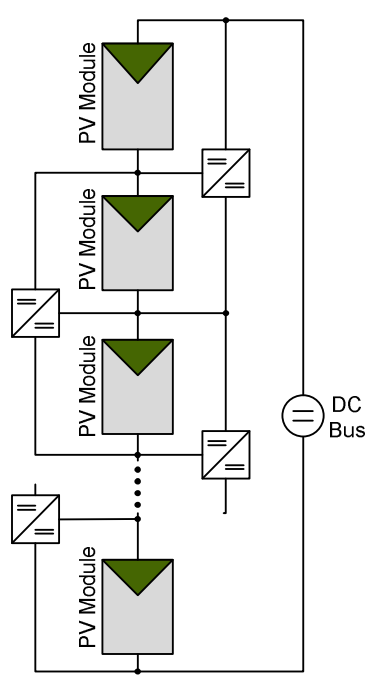

(c)

Fig. 13. Series configurations of distributed maximum power point trackers at PV module level.

\subsection{Module-Integrated-Series Inverters}

Module-integrated-series inverter (MISI) is another option to be integrated with PV modules and perform MPPT and DC/AC conversion. In contrast to the MISC, the outputs of MISI are serially connected to form a common AC bus, as shown in Fig. 13 (b). The concept indicates an ideal solution to integrate PV power generators into AC grid, which can be found in the pending patents, [72, 73]. The stack structure can build up voltage and allow each MISI to be operated at a lower DC/AC conversion ratio than the MIPI solution. The series connection of the AC terminals is generally more challenging than the DC voltage stack since the requirement for control and coordination is higher. A grid connection panel is shown in Fig. 13(b), which is important for the system configuration. The central unit is required for the safety operation and power quality assurance with the functions of grid monitoring, protection, and filtering. It also provides the communication link among the MISIs for power sharing and DMPPT operation. The drawback of such implementation also lies in the inflexibility and single power failure, which are common in any series connected system. 


\subsection{Module-Integrated-Differential-Power Processors}

Module-integrated-differential-power processors (MIDPP) were introduced to balance individual PV module operation and to eliminate mismatch, [74, 75]. The MIDPPs are multi-port DC/DC converters, which provide a bypass route in parallel with the PV strings, as shown in Fig. 13 (c). The system takes advantage of utilizing standard string configuration since the MIDPPs carry only the mismatch current, [7679]. Switched capacitor topologies were utilized to achieve the goal of differential power processing, [75]. The DC bus voltage is formed by series-connected PV modules, which can be coupled to either DC microgrids or AC grids through a centralized DC/AC inverter. The system concept sounds ideal since the power interface is active only in case of mismatch conditions. However, many constraints prevent practical implementation. Complex wiring is one of the drawbacks in comparison with other module-level DMPPT units. The reliability is not as good as the parallel structure since the series connection can be subject to short-circuit faults. Communication among all MIDPP is generally required to achieve MPPT at the module level, which adds significant cost to the system.

\section{Distributed Maximum Power Point Tracking System in PV Sub Module Level}

The submodule is a part of a PV panel consisting of 15 or 24 PV cells in series connection. Crystalline-based PV modules are commonly composed of 60 or 72 solar cells in one laminated module, which are divided into three or four submodules. The submodules are series connected with parallel connected bypass diodes. Without losing generality, the following discussion and illustration is based on the three-submodule-per-panel configuration, which is common in commercial products. Applying DMPPT at the submodule level provides even finer conversion granularity to reduce mismatch in comparison with the module-level solution, [21]. Three types of submodule based DMPPT solution are commonly presented, which include: (a) subMISC architecture; (b) subIDPP architecture; and (c) isolated-port subIDPP architecture.

\subsection{Submodule-Integrated-Series Converters}

Submodule-integrated-series converters (subMISC) are integrated with PV submodules to perform MPPT and DC/DC conversion, as shown in Fig. 14 (a). The converters are connected in series on the output side, which provides a voltage stack to form the DC-link for grid integration, [70, 80]. The DC bus formed by subMISCs can be directly linked to a DC microgrid. For AC grid interconnection, the subMISC based PV power systems process power in two stages: DC/DC and DC/AC conversion. The preferred topology is a synchronous buck converter because of its ability to step-up current as discussed in [81, 82]. The subMISCs have not been commercialized until now, however, a near commercial product is discussed in [82], of a size that can be integrated with the junction boxes of PV submodules. 
Owing to the cascaded connection of subMISCs, open-circuit failures result in the failure of a complete string, thus extra protection elements are required to avoid such a scenario. On the other hand, system malfunction can be avoided if the faulty subMISC is bypassed or short circuited. One issue that prevents the straightforward integration of subMISCs is that submodules inside commercial PV panels are internally connected in series during the lamination process. The internal connection of submodules has to be broken in order to integrate subMISCs in parallel, as shown in Fig. 14 (a). Therefore, subMISC applications require that PV panel manufacturers should take action to revise the electrical layout of PV panels prior to lamination.

\subsection{Submodule-Integrated-Differential-Power Processors}

Shown in Fig. 14 (b), an extension of MIDPP at the submodule-level is developed and known as a submodule-integrated-differential-power-processor (subIDPP), [83]. The power that is common to each submodule is processed only through the centralized DC/AC converter while the subIDPPs process only the mismatch power. The subIDPP can be realized using two different topologies: the switched-inductor converter (SLC), [83, 84]; and switched-capacitor converter (SCC), [85]. The SCC system is based on the principle of voltage equalization among all submodules. The topology cannot achieve accurate MPPT operation for each submodule when partial shading occurs, [84]. On the other hand, the SCL topology is capable of true MPPT operation through the coordination among subIDPPs. The topology and operation will be discussed in the following paragraphs.

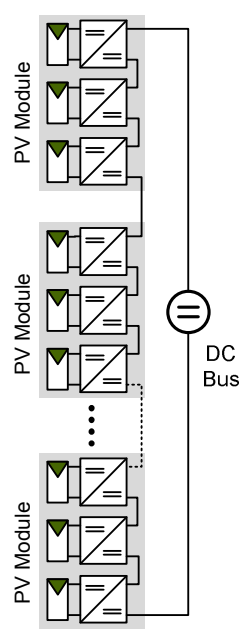

(a)

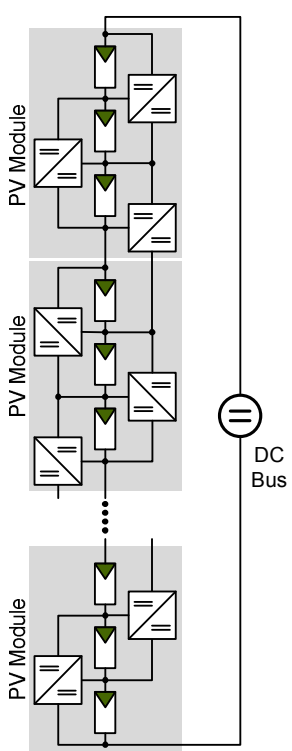

(b)

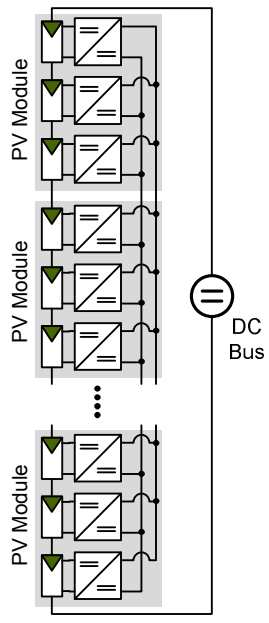

(c)

Fig. 14. Series configurations of distributed maximum power point trackers in PV submodule level.

Fig. 15 illustrates the SCL type subIDPP architecture, where PVSM refers to PV submodule. The synchronous buck-boost converter topology is utilized to form differential converters which provide 
bidirectional power flow ability between the submodules. The differential converters pass the mismatch current among submodules, while the main current flow path is still within the string of submodules. As a result, the processing loss is claimed to be lower than that of subMISC based systems, which convert the full PV power through DC/DC converters.

The series connection of submodules remains intact; therefore, the subIDPP based system can be sized, designed and constructed the same way as the conventional CMPPT system. The PV voltage requirement of determines the number of PV modules to be connected in series. The subIDPP provides additional support to improve energy harvesting only in the case of submodule mismatch. From the reliability point of view, the subIDPP system is advantageous since the connection of converters provides a parallel path which can protect the system in case of short circuit or open circuit failure of submodules, [83]. One drawback of subIDPP solution lies in the conversion efficiency, which is not competitive with the subMIC system due its complicated configuration and wide-range power operation. Another downside of the subIDPP architecture is that complex wiring is required to connect adjacent PV panels in the outdoor environment. Communication is also required to coordinate the MPPT tracking among subIDPPs.

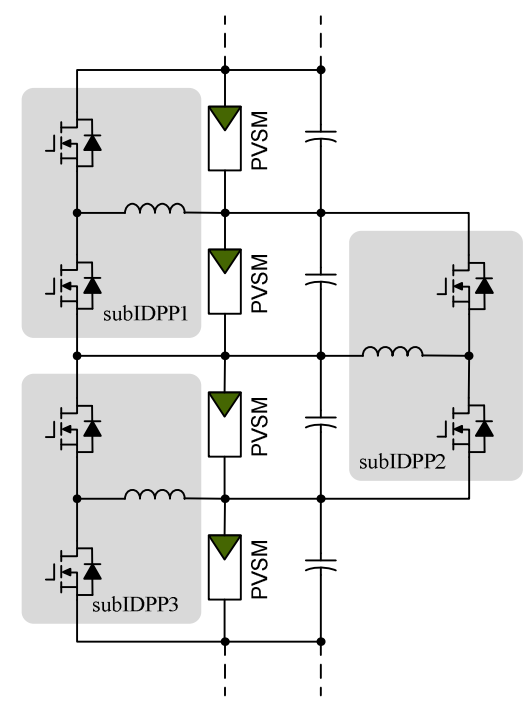

Fig. 15. Circuit diagram of switched-inductor type subIDPP architecture

\subsection{Isolated-Port Differential Power Processors}

Isolated-port differential power processors (subIPDPPs), as shown in Fig. 14 (c), have been developed which process only the differential power to eliminate the mismatch on the submodule level, $[86,87]$.

Fig 16 illustrates a circuit diagram for the subIPDPP system, which is constructed with flyback converters. The high-frequency flyback transformers provide galvanic isolation to avoid common ground problems. Each submodule is integrated in parallel with a dedicated converter, which makes it similar to subMISC in terms of connectivity. A simple control strategy of voltage equalization of submodules can be 
performed for MPPT. The converters can be turned off when no mismatch is detected. In case of unbalanced generation in submodules, the mismatch power is processed through converters to adjust the string current and eliminate the unbalanced impact. From the connectivity point of view, complex wiring is required to connect the adjacent PV panels, which makes practical implementation difficult when the outdoor environment is considered. Furthermore, the size of multiple flyback transformers is difficult to accommodate in the junction boxes of commercial PV modules. The need for additional weather-resistant enclosures for each PV module will significantly increase the installation cost.

\section{Distributed Maximum Power Point Tracking System at PV Cell Level}

An on-chip integrated power management architecture is proposed in [88] to achieve MPPT at PV cell level, of which the system diagram is shown in Fig. 17. The fully integrated circuit (IC) is claimed to eliminate partial shading issues completely. The system adopts the topology of synchronous DC/DC boost converters. To limit the size, the switching frequency is set to $500 \mathrm{kHz}$. The solution sounds ideal to push the MPPT operation to the most granular level, however, drawbacks lie in the system complexity and highcost since significant numbers of DC/DC power units are required for a typical PV grid-tied system. There is also a concern to match the DC/DC converter lifetime with the PV cells under the same harsh environment under direct sunlight. Furthermore, it is difficult to design a high-efficiency DC/DC converter for the low input voltage and high output current of a typical PV cell. For example, the maximum power output of a six-inch crystalline-based cell is about $4 \mathrm{~W}$, at $0.5 \mathrm{~V}$ and a current of $8 \mathrm{~A}$. Few studies these days focus on cell level MPPT research and implementation due to the difficulty and complexity outlined above.

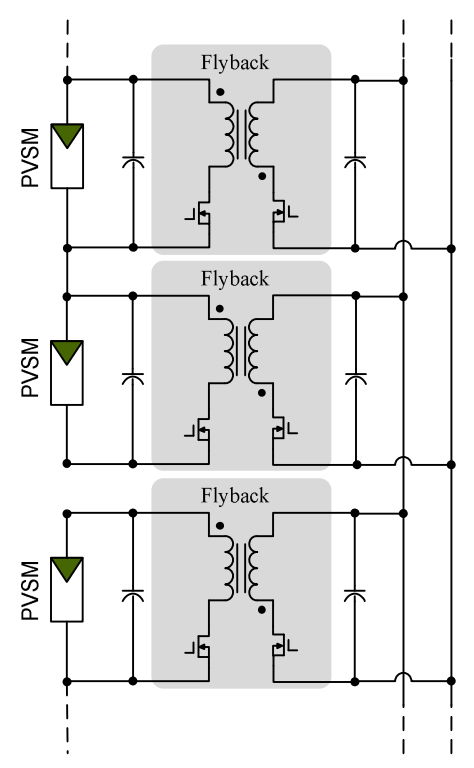

Fig. 16. Circuit diagram of subIPDPP system employing flyback converter topology. 


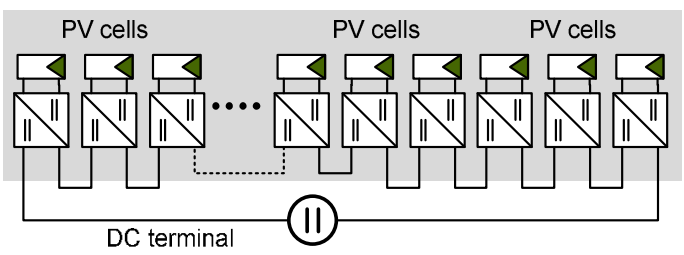

Fig. 17. On-chip integrated power management architecture to achieve MPPT at PV cell level.

\section{Conclusion}

This paper has presented a comprehensive review of grid-tied conversion topologies for PV systems. The classification adopted here differs from convention, and is focused on the level of granularity at which maximum power point tracking (MPPT) is implemented. The majority of PV grid-tied power systems can be categorized as either centralized MPPT (CMPPT) or distributed MPPT (DMPPT). The DMPPT solution is further divided into MPPT at string level, module level, submodule level, and cell level. Topologies and operation of each configuration are introduced, discussed, and analyzed. The advantages and disadvantages of each solution are compared and discussed, and promising designs for future development are identified.

The recent PV system tends to accommodate the string-level DMPPT for any scale integration. The system generally shows a good balance of high conversion efficiency and low cost implementation. The module-level DMPPT is also commercially available mainly for small scale PV systems. The conversion efficiency is relatively lower than the string-level DMPPT solution due to the significant voltage conversion ratio. It should be noted that the topology of module integrated series inverters is a promising technology, which builds the AC voltage stack that significantly reduces the conversion ratio. Due to the complication in control and implementation, the topology is currently under development for future commercialization. The submodule-level DMPPT approach is promising to be implemented in the future since it can adopt the technology of the low voltage power converters, which is well and fast developed in computer and communication devices. The voltage stack can be built to match the grid-tied required but avoid high voltage conversion ratio. However, the integration typically requires PV panel manufacturers to revise the internal electrical layout of PV panels. In general, the cost of DMPPT is higher than the CMPPT counterpart, but the technology promises the best solar energy harvest against any mismatch disturbance.

\section{References}

[1] R. Ramakumar, and J. E. Bigger, "Photovoltaic systems," Proceedings of the IEEE, vol. 81, no. 3, pp. 365-377, 1993.

[2] M. Thomson, and D. G. Infield, "Impact of widespread photovoltaics generation on distribution systems," IET Renewable Power Generation, vol. 1, no. 1, pp. 33-40, 2007.

[3] D. G. Infield, P. Onions, A. D. Simmons, and G. A. Smith, "Power quality from multiple grid-connected singlephase inverters," IEEE Transactions on Power Delivery, vol. 19, no. 4, pp. 1983-1989, 2004. 
This article has been accepted for publication in a future issue of this journal, but has not been fully edited.

Content may change prior to final publication in an issue of the journal. To cite the paper please use the doi provided on the Digital Library page.

[4] W. Xiao, F. F. Edwin, G. Spaguolo, and J. Jatskevich, "Efficient Approaches for Modeling and Simulating Photovoltaic Power Systems," IEEE Journal of Photovoltaics, vol. 3, no. 1, pp. 500-508, Jan. 2013.

[5] M. H. Wang, M.-L. Huang, and K.-J. Liou, "Islanding detection method for grid connected photovoltaic systems," IET Renewable Power Generation, vol. 9, no. 6, pp. 700-709, 2015.

[6] T. S. Basso, and R. DeBlasio, "IEEE 1547 series of standards: interconnection issues," IEEE Transactions on Power Electronics, vol. 19, no. 5, pp. 1159-1162, 2004.

[7] B. Youngsang, V. Trung-Kien, and K. Rae-Young, "Implemental Control Strategy for Grid Stabilization of Grid-Connected PV System Based on German Grid Code in Symmetrical Low-to-Medium Voltage Network," IEEE Transactions on Energy Conversion, vol. 28, no. 3, pp. 619-631, 2013.

[8] Y. Bae, T.-K. Vu, and R.-Y. Kim, "Implemental Control Strategy for Grid Stabilization of Grid-Connected PV System Based on German Grid Code in Symmetrical Low-to-Medium Voltage Network," IEEE Transactions on Energy Conversion, vol. 28, no. 3, pp. 619-631, 2013.

[9] F. Delfino, G. B. Denegri, M. Invernizzi, and R. Procopio, "Feedback linearisation oriented approach to Q-V control of grid connected photovoltaic units," IET Renewable Power Generation, vol. 6, no. 5, pp. 324-339, 2012.

[10] W. Xiao, K. Torchyan, M. Moursi, and J. Kirtley, "Online Supervisory Voltage Control for Grid Interface of Large Scale PV Plants,” IEEE Transactions on Sustainable Energy, vol. 5, no. 3, pp. 843 - 853, Jul. 2014.

[11] A. Samadi, R. Eriksson, L. Söder, B. G. Rawn, and J. C. Boemer, "Coordinated Active Power-Dependent Voltage Regulation in Distribution Grids With PV Systems," IEEE Transactions on Power Delivery, vol. 29, no. 3, pp. 1454-1464, 2014.

[12] F. Delfino, R. Procopio, M. Rossi, and G. Ronda, "Integration of large-size photovoltaic systems into the distribution grids: a p-q chart approach to assess reactive support capability," IET Renewable Power Generation, vol. 4, no. 4, pp. 329-340, 2010.

[13] L. Liu, H. Li, Y. Xue, and W. Liu, "Decoupled Active and Reactive Power Control for Large-Scale GridConnected Photovoltaic Systems Using Cascaded Modular Multilevel Converters," IEEE Transactions on Power Electronics, vol. 30, no. 1, pp. 176-187, 2015.

[14] M. Elmoursi, W. Xiao, and J. Kirtley, "Fault Ride Through Capability for Grid Interfacing Large Scale PV Power Plants," IET Generation, Transmission \& Distribution, vol. 7, no. 9, pp. 1027-1036, 2013.

[15] A. Honrubia-Escribano, T. García-Sánchez, E. Gómez-Lázaro, E. Muljadi, and A. Molina-García, "Power quality surveys of photovoltaic power plants: characterisation and analysis of grid-code requirements," IET Renewable Power Generation, vol. 9, no. 5, pp. 466-473, 2015.

[16] A. Honrubia-Escribano, T. García-Sánchez, E. Gómez-Lázaro, E. Muljadi, and A. Molina-García, "Power quality surveys of photovoltaic power plants: characterisation and analysis of grid-code requirements," IET Renewable Power Generation, 2015.

[17] W. Kou, D. Wei, P. Zhang, and W. Xiao, "A Direct Phase-Coordinates Approach to Fault Ride Through of Unbalanced Faults in Large Scale Photovoltaic Power Systems," Electric Power Components and Systems, vol. 43, no. 8-10, pp. 902-913, Jun. 2015.

[18] B. I. Craciun, T. Kerekes, D. Sera, and R. Teodorescu, "Frequency Support Functions in Large PV Power Plants With Active Power Reserves," IEEE Journal of Emerging and Selected Topics in Power Electronics, vol. 2, no. 4, pp. 849-858, 2014. 
This article has been accepted for publication in a future issue of this journal, but has not been fully edited.

Content may change prior to final publication in an issue of the journal. To cite the paper please use the doi provided on the Digital Library page.

[19] S. B. Kjaer, J. K. Pedersen, and F. Blaabjerg, "A review of single-phase grid-connected inverters for photovoltaic modules," IEEE Transactions on Industry Applications, vol. 41, no. 5, pp. 1292-1306, 2005.

[20] E. Romero-Cadaval, G. Spagnuolo, L. Franquelo, C. Ramos-Paja, T. Suntio, and W. Xiao, "Grid Connected Photovoltaic Generation Plants, Components and Operation," IEEE Industrial Electronics Magazine, vol. 7, no. 3, pp. 6-20, Sept. 2013.

[21] J. A. Abu Qahouq, and Y. Jiang, "Distributed photovoltaic solar system architecture with single-power inductor single-power converter and single-sensor single maximum power point tracking controller," IET Power Electronics, vol. 7, no. 10, pp. 2600-2609, 2014.

[22] Y. Hu, Y. Du, W. Xiao, S. Finney, and W. Cao, "DC-Link Voltage Control Strategy for Reducing Capacitance and Total Harmonic Distortion in Single-Phase Grid-Connected PV Inverters," IET Power Electronics, vol. 8, no. 8, pp. 1386-1393, Aug. 2015.

[23] L. Bowtell, and A. Ahfock, "Direct current offset controller for transformerless single-phase photovoltaic gridconnected inverters," IET Renewable Power Generation, vol. 4, no. 5, pp. 428-437, 2010.

[24] H. Hu, S. Harb, N. Kutkut, I. Batarseh, and Z. J. Shen, "A Review of Power Decoupling Techniques for Microinverters With Three Different Decoupling Capacitor Locations in PV Systems," IEEE Transactions on Power Electronics, vol. 28, no. 6, pp. 2711-2726, 2013.

[25] L. Wu, Z. Zhao, and J. Liu, "A Single-Stage Three-Phase Grid-Connected Photovoltaic System With Modified MPPT Method and Reactive Power Compensation," IEEE Transactions on Energy Conversion, vol. 22, no. 4, pp. 881-886, 2007.

[26] H. Patel, and V. Agarwal, "MPPT Scheme for a PV-Fed Single-Phase Single-Stage Grid-Connected Inverter Operating in CCM With Only One Current Sensor," IEEE Transactions on Energy Conversion, vol. 24, no. 1, pp. 256-263, 2009.

[27] T.-F. Wu, C.-H. Chang, L.-C. Lin, and C.-L. Kuo, "Power Loss Comparison of Single- and Two-Stage GridConnected Photovoltaic Systems," IEEE Transactions on Energy Conversion, vol. 26, no. 2, pp. 707-715, 2011.

[28] D. Casadei, G. Grandi, and C. Rossi, "Single-phase single-stage photovoltaic generation system based on a ripple correlation control maximum power point tracking," IEEE Transactions on Energy Conversion, vol. 21, no. 2 , pp. 562-568, 2006.

[29] S. Jain, and V. Agarwal, "A Single-Stage Grid Connected Inverter Topology for Solar PV Systems With Maximum Power Point Tracking," IEEE Transactions on Power Electronics, vol. 22, no. 5, pp. 1928-1940, 2007.

[30] T. J. Liang, Y. C. Kuo, and J. F. Chen, "Single-stage photovoltaic energy conversion system," IEE Proceedings - Electric Power Applications, vol. 148, no. 4, pp. 339-344, 2001.

[31] C. Lin, A. Amirahmadi, Z. Qian, N. Kutkut, and I. Batarseh, "Design and Implementation of Three-Phase TwoStage Grid-Connected Module Integrated Converter," IEEE Transactions on Power Electronics, vol. 29, no. 8, pp. 3881-3892, 2014.

[32] G. R. Walker, and P. C. Sernia, "Cascaded DC-DC converter connection of photovoltaic modules," IEEE Transactions on Power Electronics, vol. 19, no. 4, pp. 1130-1139, 2004.

[33] E. Roman, R. Alonso, P. Ibanez, S. Elorduizapatarietxe, and D. Goitia, "Intelligent PV Module for GridConnected PV Systems," IEEE Transactions on Industrial Electronics, vol. 53, no. 4, pp. 1066-1073, 2006. 
This article has been accepted for publication in a future issue of this journal, but has not been fully edited.

Content may change prior to final publication in an issue of the journal. To cite the paper please use the doi provided on the Digital Library page.

[34] H. Zheng, S. Li, and J. Proano, "PV energy extraction characteristic study under shading conditions for different converter configurations," in Proc. IEEE Power and Energy Society General Meeting, 2012, pp. 1-8.

[35] A. Maki, and S. Valkealahti, "Power Losses in Long String and Parallel-Connected Short Strings of SeriesConnected Silicon-Based Photovoltaic Modules Due to Partial Shading Conditions," IEEE Transactions on Energy Conversion, vol. 27, no. 1, pp. 173-183, 2012.

[36] Y. Wang, Y. Li, and X. Ruan, "High Accuracy and Fast Speed MPPT Methods for PV String Under Partially Shaded Conditions," IEEE Transactions on Industrial Electronics, vol. PP, no. 99, pp. 1-1, 2015.

[37] W. Xiao, N. Ozog, and W. G. Dunford, “Topology Study of Photovoltaic Interface for Maximum Power Point Tracking," IEEE Transactions on Industrial Electronics, vol. 54, no. 3, pp. 1696-1704, Jun. 2007.

[38] N. Femia, G. Lisi, G. Petrone, G. Spagnuolo, and M. Vitelli, "Distributed Maximum Power Point Tracking of Photovoltaic Arrays: Novel Approach and System Analysis," IEEE Transactions on Industrial Electronics, vol. 55, no. 7, pp. 2610-2621, 2008.

[39] Y. C. Chang, C. L. Kuo, K. H. Sun, and T. C. Li, "Development and Operational Control of Two-String Maximum Power Point Trackers in DC Distribution Systems," IEEE Transactions on Power Electronics, vol. 28, no. 4, pp. 1852-1861, 2013.

[40] M. S. Agamy, M. Harfman-Todorovic, A. Elasser, C. Song, R. L. Steigerwald, J. A. Sabate, A. J. McCann, Z. Li, and F. J. Mueller, "An Efficient Partial Power Processing DC/DC Converter for Distributed PV Architectures," IEEE Transactions on Power Electronics, vol. 29, no. 2, pp. 674-686, Feb. 2014.

[41] A. Urtasun, and D. D. Lu, "Control of a Single-Switch Two-Input Buck Converter for MPPT of Two PV Strings," IEEE Transactions on Industrial Electronics, vol. 62, no. 11, pp. 7051-7060, 2015.

[42] H. Keyhani, and H. A. Toliyat, "Single-Stage Multistring PV Inverter With an Isolated High-Frequency Link and Soft-Switching Operation," IEEE Transactions on Power Electronics, vol. 29, no. 8, pp. 3919-3929, 2014.

[43] L. F. Casey, M. G. Prestero, and J. Rajda, Photovoltaic DC/DC micro-converter, US8106537,to Satcon Technology Corporation, 2012.

[44] J. Viinamäki, J. Jokipii, T. Messo, T. Suntio, M. Sitbon, and A. Kuperman, "Comprehensive dynamic analysis of photovoltaic generator interfacing DC-DC boost power stage," IET Renewable Power Generation, vol. 9, no. 4, pp. 306-314, 2014.

[45] M. S. Agamy, C. Song, A. Elasser, M. Harfman-Todorovic, J. Yan, F. Mueller, and T. Fengfeng, "A HighPower-Density DC-DC Converter for Distributed PV Architectures," IEEE Journal of Photovoltaics, vol. 3, no. 2, pp. 791-798, 2013.

[46] Z. Zhao, M. Xu, Q. Chen, J.-S. Lai, and Y. Cho, "Derivation, Analysis, and Implementation of a Boost\&\#x2013;Buck Converter-Based High-Efficiency PV Inverter," IEEE Transactions on Power Electronics, vol. 27, no. 3, pp. 1304-1313, 2012.

[47] M. de Brito, L. Sampaio, G. Melo, and C. A. Canesin, "Three-phase tri-state buck-boost integrated inverter for solar applications," IET Renewable Power Generation, vol. 9, no. 6, pp. 557-565, 2015.

[48] M. Kasper, D. Bortis, and J. W. Kolar, "Classification and Comparative Evaluation of PV Panel-Integrated DCDC Converter Concepts," IEEE Transactions on Power Electronics, vol. 29, no. 5, pp. 2511-2526, 2014.

[49] J. Puukko, and T. Suntio, "Dynamic properties of a voltage source inverter-based three-phase inverter in photovoltaic application," IET Renewable Power Generation, vol. 6, no. 6, pp. 381-391, 2012. 
This article has been accepted for publication in a future issue of this journal, but has not been fully edited.

Content may change prior to final publication in an issue of the journal. To cite the paper please use the doi provided on the Digital Library page.

[50] M. Hanif, V. Khadkikar, W. Xiao, and J. Kirtley, "Two Degrees of Freedom Active Damping Technique for an LCL Filter Based Grid Connected PV Systems,” IEEE Transactions on Industrial Electronics, vol. 61, no. 6, pp. 2795-2803, Jun. 2014.

[51] G. Petrone, G. Spagnuolo, and M. Vitelli, “An Analog Technique for Distributed MPPT PV Applications,” IEEE Transactions on Industrial Electronics, vol. 59, no. 12, pp. 4713-4722, 2012.

[52] B. Sahan, A. N. Vergara, N. Henze, A. Engler, and P. Zacharias, "A Single-Stage PV Module Integrated Converter Based on a Low-Power Current-Source Inverter," IEEE Transactions on Industrial Electronics, vol. 55, no. 7, pp. 2602-2609, 2008.

[53] S.-M. Chen, T.-J. Liang, L.-S. Yang, and J.-F. Chen, "A Boost Converter With Capacitor Multiplier and Coupled Inductor for AC Module Applications," IEEE Transactions on Industrial Electronics, vol. 60, no. 4, pp. 1503-1511, 2013.

[54] Y. Zhou, L. Liu, and H. Li, "A High-Performance Photovoltaic Module-Integrated Converter (MIC) Based on Cascaded Quasi-Z-Source Inverters (qZSI) Using eGaN FETs," IEEE Transactions on Power Electronics, vol. 28, no. 6, pp. 2727-2738, 2013.

[55] R. K. Surapaneni, and A. K. Rathore, "A Single-Stage CCM Zeta Microinverter for Solar Photovoltaic AC Module," IEEE Journal of Emerging and Selected Topics in Power Electronics, vol. 3, no. 4, pp. 892-900, 2015.

[56] F. F. Edwin, W. Xiao, and V. Khadkikar, "Dynamic Modeling and Control of Interleaved Flyback Module Integrated Converter for PV Power Applications," IEEE Transactions on Industrial Electronics, vol. 61, no. 3, pp. 1377-1388, Mar. 2014.

[57] F. F. Edwin, W. Xiao, and V. Khadkikar, "Topology Review of Single Phase Grid-Connected Module Integrated Converters for PV Applications," in Proc. Annual Conference of IEEE Industrial Electronics Society, 2012, pp. 821-827.

[58] A. C. Nanakos, E. C. Tatakis, and N. P. Papanikolaou, "A Weighted-Efficiency-Oriented Design Methodology of Flyback Inverter for AC Photovoltaic Modules," IEEE Transactions on Power Electronics, vol. 27, no. 7, pp. 3221-3233, 2012.

[59] B. Chen, B. Gu, L. Zhang, Z. U. Zahid, J. S. J. Lai, Z. Liao, and R. Hao, "A High-Efficiency MOSFET Transformerless Inverter for Nonisolated Microinverter Applications," IEEE Transactions on Power Electronics, vol. 30, no. 7, pp. 3610-3622, 2015.

[60] S. A. Arshadi, B. Poorali, E. Adib, and H. Farzanehfard, "High Step-Up DC-AC Inverter Suitable for ACModule Applications," IEEE Transactions on Industrial Electronics, vol. PP, no. 99, pp. 1-1, 2015.

[61] Y. Fang, and X. Ma, “A Novel PV Microinverter With Coupled Inductors and Double-Boost Topology," IEEE Transactions on Power Electronics, vol. 25, no. 12, pp. 3139-3147, 2010.

[62] N. Kasa, T. Iida, and C. Liang, "Flyback Inverter Controlled by Sensorless Current MPPT for Photovoltaic Power System," IEEE Transactions on Industrial Electronics, vol. 52, no. 4, pp. 1145-1152, 2005.

[63] Q. Li, and P. Wolfs, "A Review of the Single Phase Photovoltaic Module Integrated Converter Topologies With Three Different DC Link Configurations," IEEE Transactions on Power Electronics, vol. 23, no. 3, pp. 13201333, 2008.

[64] M. Chen, K. K. Afridi, and D. J. Perreault, "A Multilevel Energy Buffer and Voltage Modulator for GridInterfaced Microinverters," IEEE Transactions on Power Electronics, vol. 30, no. 3, pp. 1203-1219, 2015. 
This article has been accepted for publication in a future issue of this journal, but has not been fully edited.

Content may change prior to final publication in an issue of the journal. To cite the paper please use the doi provided on the Digital Library page.

[65] B. J. Pierquet, and D. J. Perreault, "A Single-Phase Photovoltaic Inverter Topology With a Series-Connected Energy Buffer," IEEE Transactions on Power Electronics, vol. 28, no. 10, pp. 4603-4611, Oct. 2013.

[66] N. Femia, G. Petrone, G. Spagnuolo, and M. Vitelli, Power Electronics and Control Techniques for Maximum Energy Harvesting in Photovoltaic Systems: CRC Press, 2012.

[67] G. Krzywinski, "Integrating storage and renewable energy sources into a DC Microgrid using high gain DC DC Boost Converters," in Proc. IEEE First International Conference on DC Microgrids (ICDCM), 2015, pp. 251256.

[68] Y. Hu, W. Cao, S. Finney, W. Xiao, F. Zhang, and S. McLoone, "New Modular Structure DC-DC Converter Without Electrolytic Capacitors for Renewable Energy Applications," IEEE Transactions on Sustainable Energy, vol. 5, no. 4, pp. 1184-1192, Oct. 2014.

[69] Y. Hu, J. Wu, W. Cao, W. Xiao, P. Li, S. Finney, and Y. Li, "Ultra-High Step-up DC-DC Converter for Distributed Generation by Three Degrees of Freedom (3DoF) Approach," IEEE Transactions on Power Electronics, vol. 31, no. 7, pp. 4930 - 4941, Jul. 2016.

[70] O. Khan, W. Xiao, and H. Zeineldin, "Gallium Nitride Based Submodule Integrated Converters for HighEfficiency Distributed Maximum Power Point Tracking PV Applications," IEEE Transactions on Industrial Electronics, vol. 63, no. 2, pp. 966-975, Feb. 2016.

[71] E. Roman, P. Ibanez, S. Elorduizapatarietxe, R. Alonso, D. Goitia, and I. M. de Alegria, "Intelligent PV module for grid-connected PV systems," in Proc. 30th Annual Conference of IEEE Industrial Electronics Society, 2004, pp. 3082-3087 Vol. 3.

[72] B. Johnson, P. Krein, A. Gray, and P. L. Chapman, "Inverter array with localized inverter control," US20120134186 A1, SolarBridge Technologies, 2012.

[73] G. Deboy, R. Bruendlinger, F. Andrèn, and F. Lehfuss, "Power Converter Circuit with AC Output," US20130009700 A1, Infineon Technologies Ag, 2013.

[74] A. Blumenfeld, A. Cervera, and M. M. Peretz, "Enhanced differential power processor for PV systems: Resonant switched-capacitor gyrator converter with local MPPT," in Proc. Twenty-Ninth Annual IEEE Applied Power Electronics Conference and Exposition (APEC), 2014, pp. 2972-2979.

[75] A. Blumenfeld, A. Cervera, and M. M. Peretz, "Enhanced Differential Power Processor for PV Systems: Resonant Switched-Capacitor Gyrator Converter With Local MPPT," IEEE Journal of Emerging and Selected Topics in Power Electronics, vol. 2, no. 4, pp. 883-892, 2014.

[76] N. Pragallapati, and V. Agarwal, "Distributed PV Power Extraction Based on a Modified Interleaved SEPIC for Nonuniform Irradiation Conditions," IEEE Journal of Photovoltaics, vol. 5, no. 5, pp. 1442-1453, 2015.

[77] P. Sharma, and V. Agarwal, "Exact Maximum Power Point Tracking of Grid-Connected Partially Shaded PV Source Using Current Compensation Concept," IEEE Transactions on Power Electronics, vol. 29, no. 9, pp. 4684-4692, 2014.

[78] P. Sharma, and V. Agarwal, "Maximum Power Extraction From a Partially Shaded PV Array Using ShuntSeries Compensation," IEEE Journal of Photovoltaics, vol. 4, no. 4, pp. 1128-1137, 2014.

[79] M. Uno, and A. Kukita, "Single-Switch Voltage Equalizer Using Multistacked Buck-Boost Converters for Partially Shaded Photovoltaic Modules," IEEE Transactions on Power Electronics, vol. 30, no. 6, pp. 30913105, 2015. 
This article has been accepted for publication in a future issue of this journal, but has not been fully edited.

Content may change prior to final publication in an issue of the journal. To cite the paper please use the doi provided on the Digital Library page.

[80] O. Khan, and W. Xiao, "An Efficient Modeling Technique to Simulate and Control Submodule-Integrated PV System for Single-Phase Grid Connection," IEEE Transactions on Sustainable Energy, vol. PP, no. 99, pp. 1-12, 2015.

[81] F. Wang, X. Wu, F. C. Lee, Z. Wang, P. Kong, and F. Zhuo, "Analysis of Unified Output MPPT Control in Subpanel PV Converter System," IEEE Transactions on Power Electronics, vol. 29, no. 3, pp. 1275-1284, 2014.

[82] R. C. N. Pilawa-Podgurski, and D. J. Perreault, "Submodule Integrated Distributed Maximum Power Point Tracking for Solar Photovoltaic Applications," IEEE Transactions on Power Electronics, vol. 28, no. 6, pp. 2957-2967, 2013.

[83] P. S. Shenoy, K. A. Kim, B. B. Johnson, and P. T. Krein, "Differential Power Processing for Increased Energy Production and Reliability of Photovoltaic Systems," IEEE Transactions on Power Electronics, vol. 28, no. 6, pp. 2968-2979, 2013.

[84] S. Qin, S. T. Cady, A. D. Dominguez-Garcia, and R. C. N. Pilawa-Podgurski, "A Distributed Approach to Maximum Power Point Tracking for Photovoltaic Submodule Differential Power Processing," IEEE Transactions on Power Electronics, vol. 30, no. 4, pp. 2024-2040, Apr. 2015.

[85] J. T. Stauth, M. D. Seeman, and K. Kesarwani, "Resonant Switched-Capacitor Converters for Sub-module Distributed Photovoltaic Power Management," IEEE Transactions on Power Electronics, vol. 28, no. 3, pp. 1189-1198, 2013.

[86] Y. Levron, D. R. Clement, C. Beomseok, C. Olalla, and D. Maksimovic, "Control of Submodule Integrated Converters in the Isolated-Port Differential Power-Processing Photovoltaic Architecture," IEEE Journal of Emerging and Selected Topics in Power Electronics, vol. 2, no. 4, pp. 821-832, Dec. 2014.

[87] C. Olalla, D. Clement, M. Rodriguez, and D. Maksimovic, "Architectures and Control of Submodule Integrated DC-DC Converters for Photovoltaic Applications," IEEE Transactions on Power Electronics, vol. 28, no. 6, pp. 2980-2997, Jun. 2013.

[88] A. Shawky, F. Helmy, M. Orabi, J. A. Qahouq, and D. Zhigang, "On-chip integrated cell-level power management architecture with MPPT for PV solar system," in Proc. Twenty-Ninth Annual IEEE Applied Power Electronics Conference and Exposition (APEC), 2014, pp. 572-579. 